\title{
El movimiento obrero organizado ante la ofensiva de la oligarquía financiera
}

\author{
Argentina, 2016-2019
}

Nicolás Iñigo Carrera*

https://orcid.org/0000-0003-1092-0030

Fabián Fernández*

https://orcid.org/0000-0001-8637-1141

María Celia Cotarelo*

https://orcid.org/0000-0002-5053-7311

Introducción

En noviembre de 2015 la alianza electoral Cambiemos se impuso por escaso margen en el balotaje de las elecciones presidenciales y consagró presidente de la Nación al empresario Mauricio Macri. Su programa económico ${ }^{1}$ tenía muchos puntos en común con el que había implementado el gobierno cívico militar surgido del golpe de estado de 1976 y con el que sostuviera el ministro Domingo Cavallo durante los gobiernos de Carlos Menem y Fernando de la Rúa. Era el retorno de las llamadas "políticas neoliberales", sustentadas en el voto de la mitad de la ciudadanía, lo que constituía un paso más de la oligarquía financiera en la lucha por la construcción de su hegemonía. Sin embargo, previendo una fuerte resistencia, el nuevo gobierno se planteó un avance cauteloso ("gradualismo") en las reformas más profundas (reducción del empleo estatal, eliminación de conquistas laborales, extensión de la edad jubilatoria) y finalmente no las pudo imponer plenamente. Pero los resultados

* Universidad de Buenos Aires, Buenos Aires, Argentina.

1. En sus primeros meses de gobierno Macri eliminó o redujo las "retenciones" (impuesto) a las exportaciones de cereales y oleaginosas, de productos industriales y de origen agropecuario; subió las tasas de interés; eliminó todas las restricciones y controles cambiarios y las restricciones a las exportaciones; bajó alícuotas de impuestos de algunos artículos suntuarios; aumentó las tarifas de los servicios públicos; pagó la deuda con fondos de inversión especulativos y volvió al mercado internacional de deuda, primero privado y después con el FMI. A la vez, incrementó los “planes sociales" (subsidios a la población que no puede obtener sus medios de vida en la actividad económica). 
de su política fueron, para la clase obrera, un aumento de la desocupación abierta, la caída del salario real gracias al proceso inflacionario y el aumento notable de la población sumergida en la pobreza.

\section{Argentina 1976-2015}

\section{La ofensiva de fuerza social acaudillada por la oligarquía financiera (1975-2001)}

Ese retorno marcaba la continuidad del período contrarrevolucionario iniciado a mediados de la década de 1970, cuando la fuerza social acaudillada por la oligarquía financiera se impuso mediante el uso de la fuerza material subordinando a la fuerza del capital menos concentrado y aniquilando a la fuerza social que postulaba la superación del capitalismo. Se rompía así la traba impuesta por el agotamiento del desarrollo del capitalismo en extensión predominando entonces el desarrollo en profundidad, con un desarrollo de las fuerzas productivas en determinadas ramas, a la vez que generaba una creciente masa de población sobrante para las necesidades del capital (Iñigo Carrera, 2010), que comenzó a hacerse visible en la década de 1980 y fue incrementándose hasta alcanzar aproximadamente a $60 \%$ del proletariado (Donaire et al., 2018). La existencia de esa masa de superpoblación relativa permitió mantener las condiciones desfavorables para la clase obrera (caída del salario, extensión de la jornada laboral, flexibilización), en un comienzo impuestas por la fuerza de las armas, cuando los cuadros militares entregaron el gobierno a los cuadros políticos surgidos de elecciones en 1983. Impuesta la nueva organización de la sociedad los siguientes veinticinco años, hasta los comienzos del nuevo siglo, contemplaron su desarrollo y el intento por construir el necesario consenso, en buena medida, sobre la base del miedo. El dominio de la oligarquía financiera se hizo hegemónico después de las hiperinflaciones de 1989 y 1990, que crearon las condiciones para una nueva ofensiva del capital financiero a partir de abril de 1991, con el Plan de Convertibilidad del ministro Cavallo. Este plan, que estableció la paridad entre el peso y el dólar, incluyó una mayor "desregulación" de la economía ${ }^{2}$ la privatización de las empresas de servicios públicos, una mayor apertura de las importaciones, mayor endeudamiento y culminó en la recesión económica que se extendió entre 1998 y 2002, incluyendo la crisis política de 2001-2002.

La descripta ofensiva de la oligarquía financiera, iniciada en la década de 1970 y reforzada en la década de 1990, continuó con Fernando de la Rúa (Alianza UCR-Frepaso) que sucedió a Carlos Menem (Partido Justicialista) en la presidencia.

2. Bajo ese nombre se establecieron regulaciones que favorecían a los capitales más concentrados. 
La aprobación de una reforma laboral exigida por el FMI legalizó las condiciones de máxima jornada de trabajo con mínimo salario, tanto en las grandes empresas como en las pequeñas. El cuadro se completó con la disminución del salario no sólo en términos reales sino también nominales, el despojo de condiciones conquistadas históricamente y el crecimiento de la masa de población sobrante para el capital, que se hundía en la pobreza, consolidándose en la miseria. Su manifestación más visible, la desocupación abierta, alcanzó cifras nunca vistas: si hasta fines de los '80 las tasas de desocupación habían oscilado entre el 3 y $6 \%$ de la PEA, en la segunda mitad de la década de 1990 la tasa de desocupación más baja fue de 12,4\% y a comienzos del nuevo siglo superó el 20\%. A fines de los años '90 el 20\% más rico de la población recibía el 51,6\% del ingreso total mientras el 20\% más pobre recibía apenas el 4,2\% (Bermúdez, 1998).

Frente a la ofensiva de la oligarquía financiera hubo distintas formas de resistencia protagonizadas por la clase obrera organizada sindical y políticamente. Una clase obrera con una larga tradición de lucha, frecuentemente con huelgas generales de alcance nacional, y una organización centralizada, que en 2014/15 abarcaba al 39\% de los asalariados registrados de los sectores privado (35\%) y público (46\%) (Tomada et al., 2018), mayoritariamente peronista, aunque con presencia de organizaciones de izquierda. Esa tradición sindical explica la rápida organización de la creciente superpoblación relativa en las llamadas organizaciones piqueteras, que tienden a consolidarse como sindicatos de las capas pobres de la clase obrera.

En ese proceso de resistencia se fue conformando un movimiento de oposición a las políticas llamadas neoliberales y a los gobiernos que las implementaban, que culminó en la insurrección espontánea de diciembre de 2001.

\section{La resistencia}

Desde el inicio del período contrarrevolucionario en 1976 y hasta la insurrección espontánea de diciembre de 2001 fueron convocadas 37 huelgas generales: 5 bajo el gobierno militar, 13 durante el gobierno de Raúl Alfonsín, 9 durante el gobierno de Carlos Menem y 9 durante el de Fernando De la Rúa. La mayoría recibió una adhesión de al menos el 50\% de los trabajadores, varias tuvieron una adhesión superior al 75\% y algunas superior al 90\%. 25 de esas huelgas generales fueron convocadas por la Confederación General del Trabajo (CGT) ${ }^{3}$.

3. La CGT fue fundada en 1930 por la fusión de las dos principales centrales existentes. En 1950 reformó su estatuto y se incorporó como rama sindical del Partido Peronista, situación que abandonó con el derrocamiento del gobierno de Perón. Sin embargo, su dirigencia, salvo pocas excepciones es peronista, Desde su misma fundación ha sufrido divisiones (lo que dio lugar muchas veces a la existencia simul- 
De ellas participaron no sólo los trabajadores ocupados y sindicalizados: las huelgas generales convocadas “con movilización” articularon simultáneamente en todo el país (aunque con especificidades regionales) la protesta y la lucha de distintas fracciones y capas de la clase obrera, incluyendo los más pobres, los ocupados y desocupados, constituyéndose como lucha política del conjunto de la clase obrera, e incorporando a otras fracciones sociales. Lo mismo ocurrió con otras grandes movilizaciones como la Marcha Federal en 1994 y la Marcha Nacional por el Trabajo en 1997, que recorrieron el país desde Jujuy y la Patagonia hacia Buenos Aires, convocadas por las centrales sindicales Central de Trabajadores de Argentina (CTA) y Movimiento de los Trabajadores Argentinos (MTA), corrientes político sindicales como la Corriente Clasista y Combativa (CCC) y organizaciones de pequeños empresarios y de estudiantes, con la adhesión de partidos políticos opositores. La CTA, en 1992, y el MTA (que más tarde retomó el nombre de CGT, con la conducción del camionero Hugo Moyano), en 1994, surgieron como escisiones de la CGT, cuya dirección apoyó algunas políticas del presidente Menem, incluyendo la privatización de empresas públicas.

Después de un largo momento descendente que se inició en 1988 (Iñigo Carrera, 2002), en que las luchas obreras fueron sistemáticamente derrotadas (telefónicos 1990, ferroviarios y mineros 1991, metalúrgicos 1992), mientras el crecimiento del desempleo debilitaba al movimiento sindical, comenzaron a crecer otras formas de organización y de lucha, protagonizadas por la creciente superpoblación relativa. Sindicatos locales y nacionales, comisiones internas junto con organizaciones de desocupados y las centrales citadas tuvieron un importante papel en las huelgas y cortes de ruta que signaron el ciclo de rebelión ${ }^{4}$ delimitado entre el motín de

tánea de dos CGT) y reunificaciones. Fue intervenida y disuelta por el gobierno militar en 1976, pero mantuvo su poder de convocatoria y se reconstituyó a comienzos de los años '80. El "modelo sindical argentino" sólo reconoce personería gremial a una organización por actividad y a una central sindical, permite la presencia de la organización en el lugar de trabajo a la vez que tiende al centralismo burocrático. Esto fortalece el poder de la CGT.

4. Concebimos el concepto de ciclo de rebelión por analogía con el concepto de ciclo industrial, una "secuencia de períodos de animación mediana, prosperidad, sobreproducción, crisis y estancamiento" (Marx, 1983, p. 551). Un ciclo de rebelión presenta grados crecientes de 'animación' de la protesta y de la lucha hasta un momento de extensión generalizada, que lleva a una crisis mediante la cual se realiza una nueva relación de fuerzas, quedando planteada la posibilidad de renovación del ciclo en un movimiento que se desarrolla en espiral. El criterio central para la delimitación de un ciclo es que la forma de lucha más elevada contiene a las formas inferiores, que forman parte de un mismo proceso. Es esa unidad constituida por la confluencia de diversos elementos lo que permite distinguirlo como un ciclo. Dentro de un ciclo delimitamos fases ascendentes o descendentes mirando el proceso desde la clase obrera, atendiendo a los grados de unidad o fractura a su interior y de alianza o aislamiento de la misma con respecto a otras fracciones sociales. Difiere del concepto "ciclo de protesta" o "de acción contenciosa” (cycle of contention) formulado por Tarrow (1998, p. 142) porque éste entraña el peligro 
Santiago del Estero (diciembre de 1993) y la insurrección espontánea (diciembre de 2001), que puede prolongarse hasta junio de 2002 (enfrentamiento de Puente Pueyrredón-Avellaneda) (Cotarelo y Iñigo Carrera, 2005).

\section{La formación de una fuerza social democrático popular}

En diciembre de 1993 una huelga de docentes y empleados públicos en la provincia de Santiago del Estero derivó en un motín popular: fueron incendiadas la casa de gobierno, la legislatura y los tribunales de justicia así como las casas de algunos políticos (Cotarelo, 1999), dando inicio a una serie de hechos similares que se multiplicaron en 1995. Poco después, en 1996, 20.000 personas cortaron la ruta en la patagónica ciudad petrolera de Cutral-Có y las tropas de Gendarmería no pudieron impedirlo. La misma forma de lucha fue utilizada en 1997 en Jujuy (Gómez y Kindgard, 1998), nuevamente en Cutral Có (Neuquén) (Klachko, 2002), Cruz del Eje (Córdoba) y Tartagal (Salta) (Polischuk y Rojze, 2017), en los que surgieron embriones de oposición no sólo al gobierno y sus políticas sino también contra el régimen político mismo. En los años siguientes se multiplicaron los cortes de rutas y de calles, algunos masivos, que dieron lugar a formas asamblearias de democracia directa.

Al ciclo de rebelión iniciado en diciembre 1993 y hasta junio de 2002, corresponden 19 huelgas generales ( 14 de ellas con una adhesión superior al 50\%; algunas con más del $75 \%$ e incluso del $90 \%$ ). Las masivas huelgas generales convocadas por la CGT, por momentos enfrentada al gobierno de Menem, en 1995 y 1996, y la amenaza de convocar a una huelga general por tiempo indeterminado, junto con los masivos cortes de rutas de 1997 (lucha de barricadas) citados en el párrafo anterior, forzaron al gobierno nacional a detener las reformas proyectadas, entre ellas un cambio en la legislación laboral que recortaba derechos de los trabajadores. Esa tarea la realizó el gobierno surgido de las elecciones de 1999, encabezado por Fernando de la Rúa, con el enorme costo político que significó la sospecha de pago de sobornos a algunos senadores que votaron la ley de reforma laboral: fue el comienzo del fin de ese gobierno que duró apenas dos años. La resistencia se manifestó en enfrentamientos sociales en Corrientes (1999) (Klachko, 2002) y en Salta (Tartagal y General Mosconi) (2000 y 2001), y en tres huelgas generales en 2000 y seis en 2001. A comienzos de este último año, los "cortes de ruta" masivos, protagonizados por miles de piqueteros, alcanzaron al Gran Buenos Aires y se extendieron por varios días. En un proceso que se prolongó en las décadas siguientes se formaron las organizaciones llamadas tereses de clase en juego, a los cambios en el carácter de la lucha, a la identificación de clase de los sujetos. 
“piqueteras", que expresan los intereses inmediatos de las capas pobres de la población (en adelante OCP): Corriente Clasista y Combativa (CCC), Federación de Tierra y Vivienda (FTV), Polo Obrero (PO), Frente Darío Santillán (FDS), Movimiento Teresa Vive (MST), Movimiento Evita; más tarde la Confederación de Trabajadores de la Economía Popular (CTEP) 5 .

El movimiento de oposición a las políticas de gobierno y a los gobiernos mismos encabezados sucesivamente por los presidentes Menem y de la Rúa dio lugar a la formación de una fuerza social caracterizada como democrática, popular y nacional/ antiimperialista (Cotarelo, 2016) (en adelante FSDP), que recorrió toda Argentina y emergió en la insurrección espontánea de diciembre de 2001. En el lapso de doce días hubo cinco diferentes presidentes o encargados del Poder Ejecutivo.

El movimiento obrero organizado sindicalmente tuvo una importante participación en la resistencia contra las medidas neoliberales, aunque con fuertes discrepancias entre las corrientes y centrales sindicales - ya que la CGT aceptó y avaló muchas de las medidas tomadas por los gobiernos de Menem y de la Rúa mientras que el MTA (después CGT-Moyano) y la CTA las rechazaron sistemáticamente. Pero cuando unificaron su lucha en las huelgas generales con movilización tuvieron la capacidad de articular las luchas de otras fracciones sociales en todo el país. Sin embargo, su lucha se circunscribió a oponerse a las políticas de gobiernos neoliberales, sin cuestionar el sistema mismo, y después de la insurrección espontánea de diciembre de 2001, contribuyeron, mediante su participación en la Mesa de Diálogo Argentino, a la reconstrucción del sistema institucional.

\section{Cambio de la alianza social en el gobierno 2002-2015}

Después de la insurrección de 2001 los gobiernos cambiaron la política económica, se declaró en default la deuda pública y se produjo una fuerte devaluación del peso. Los recursos fiscales resultantes de estas medidas fueron dirigidos a subsidiar a las empresas de servicios públicos, cuyas tarifas fueron congeladas, a aumentar los subsidios para los desocupados y capas pobres y a actividades productivas. El PBI creció a tasas de $9 \%$ anual durante los cinco años siguientes, mientras bajaba el desempleo, y subían los salarios reales. El índice de pobreza registrada pasó de 47,8\% en 2003 a 23,4\% en 2007 (Galak, 2007; Stang, 2007).

5. Sólo nombramos a algunas de las organizaciones más numerosas y con mayor protagonismo en los últimos cuatro años. Algunas de ellas (CCC, PO, MST) están vinculadas a partidos de izquierda. Otros (Movimiento Evita) son peronistas. Otros son antiimperialistas y anticapitalistas sin estar directamente ligadas a un partido. Todas tienden a convertirse en organizaciones sindicales de la superpoblación relativa. 
Entre junio de 2002 y abril de 2003, toda la actividad política y sindical se canalizó hacia la confrontación electoral. Finalmente Néstor Kirchner fue electo presidente de la Nación, siendo sucedido por Cristina Fernández de Kirchner en 2007, reelecta en 2011.

Los gobiernos Kirchner se sostuvieron en una alianza entre fracciones de burguesía personificación de capital menos concentrado y la mayoría del movimiento obrero y popular. La oligarquía financiera los toleró en la medida en que se recomponía el sistema institucional, alterado por la acción de las masas que culminó en la insurrección espontánea de $2001^{6}$.

Estos gobiernos asumieron varias de las banderas de la FSDP gestada en el ciclo 1993-2001, que vio realizadas algunas de sus metas. Sin embargo no puede afirmarse que existiera una correspondencia total entre gobiernos kirchneristas y la FSDP: formaron parte de esos gobiernos cuadros políticos ajenos a esa fuerza ( $y$ con vínculos con el capital financiero) y no todos los componentes de la FSDP apoyaron a los gobiernos kirchneristas. A la vez se reforzó el proceso de reconstitución del sistema institucional: desde la convocatoria a las elecciones presidenciales de 2003, desapareció del centro de la escena el movimiento social que se manifestaba por fuera o en contra del sistema institucional vigente; todo se canalizó dentro de éste (Cotarelo, 2016).

El movimiento obrero organizado sindicalmente se alineó mayoritariamente en apoyo al gobierno kirchnerista, pero no ocupó un lugar preponderante en el gobierno. Sin embargo, logró recuperar espacios en el sistema institucional: la anulación de la reforma laboral de 2000, la convocatoria a paritarias por rama de actividad, aumento del salario real, etc. Durante siete años (junio de 2002 hasta abril de 2009) no se declararon huelgas generales contra el gobierno o sus políticas; las únicas realizadas en ese lapso gozaron de simpatía gubernamental: fueron contra la formación de un Área de Libre Comercio de las Américas (Alca) y la presencia en Argentina de George W. Bush (declarada por la CTA el $4 / 11 / 2005$ ) y en repudio al asesinato del docente Carlos Fuentealba por la policía de la provincia de Neuquén, cuyo gobernador se postulaba como candidato a presidente opositor al gobierno nacional (declarada por la CTA y la CGT el 9/4/2007). Fue un momento de alto grado de unidad tanto en la acción como en el plano institucional (la CGT se unificó en 2004); y también de alianza con otras fracciones sociales.

6. Aunque la base social de la fuerza oligárquica se movilizó contra el gobierno desde su inicio (marchas contra la inseguridad, por los valores cristianos etc.) fue a partir de 2008 en que pasó a la ofensiva con la movilización de la burguesía y pequeña burguesía agropecuarias. 
Momento descendente: fractura del movimiento obrero y crisis de la alianza social en el gobierno

La crisis económica mundial de 2008, con la caída en los precios de las materias primas, que afectó a las exportaciones argentinas, puso fin a cinco años de constante crecimiento. Si bien hubo una recuperación en 2010 y 2011, 2012 y 2013 fueron años en que el crecimiento se desaceleró y los años siguientes fueron de estancamiento y retracción, con caída de la producción industrial, de los salarios reales y crecimiento de la inflación (Kulfas, 2016), que rondó el 25\% anual. El gobierno tomó medidas como la creación de la Asignación Universal por Hijo, dirigida a paliar la situación de las capas más pobres. En diciembre de 2015, el Observatorio de la Deuda Social de la Universidad Católica Argentina estimaba que el 29\% de la población estaba bajo la línea de pobreza (Jueguen 2019).

Los primeros indicios de fractura en el movimiento obrero se hicieron evidentes con motivo del enfrentamiento entre el gobierno y las organizaciones patronales del campo que se desarrolló entre marzo y junio de 2008 (Cotarelo, 2016): aunque la mayoría de la CGT y la CTA apoyaron al gobierno nacional, el sindicato de trabajadores rurales (Uatre) se alineó junto con sus patrones; otro grupo de sindicatos también manifestó su oposición al gobierno y en julio formó la CGT Azul y Blanca.

En 2009 una parte de la CTA convocó a dos huelgas generales (22/4 y 27/5) reclamando aumentos salariales y de las jubilaciones, prohibición de despidos, universalización de subsidios y personería de la central. Pero no todos los gremios de la CTA apoyaron las huelgas, que recibieron poca adhesión, y tuvieron más repercusión las movilizaciones y actos callejeros que la huelga misma. Esa fractura en los cuadros de la CTA se institucionalizó en 2010, teniendo a Hugo Yasky y Pablo Micheli como secretarios generales de cada una de las fracciones; la primera, que sin dejar de expresar reclamos salariales, apoyó las políticas del gobierno nacional, tomó el nombre de CTA de los Trabajadores, la segunda, netamente opositora, tomó el nombre de CтA Autónoma.

En 2011 Cristina Kirchner fue reelegida presidenta de la Nación con más del 54\% de los votos. Pero en 2012 otra parte del movimiento obrero, encabezada por Hugo Moyano, quedó fuera de la alianza en el gobierno. La CGT se dividió en CGT Azopardo y CGT Alsina, que tuvieron como secretarios generales a Hugo Moyano y a Antonio Caló, respectivamente. El primero pasó a la oposición política después de haber reclamado inútilmente mayor espacio en las listas de candidatos a diputados y senadores para los sindicalistas y la candidatura a la vicepresidencia de la Nación para alguien vinculado al movimiento sindical; el segundo, por el contrario, resaltó la mejoría de la situación económica y laboral resultantes de las políticas del gobierno y mantuvo su apoyo. 
El movimiento obrero organizado sindicalmente se encontró dividido en cinco centrales diferentes: tres CGT (Alsina, Azopardo y Azul y Blanca) y dos CTA (de los Trabajadores y Autónoma).

La fractura del movimiento sindical se expresó en las acciones: entre abril de 2009 y octubre de 2012 fueron convocadas siete huelgas generales contra políticas del gobierno nacional ${ }^{7}$; en las cuatro realizadas entre 2009 y 2011 convocó la parte de la CTA que se denominaría Autónoma; las de 2012 las convocaron la CTA Autónoma, la CGT-Azopardo y CGT Azul y Blanca. En todas ellas, lo mismo que en una convocada por la CTA Autónoma en 2013, el paro pasó casi desapercibido y tuvieron las características de "jornadas de lucha”, con manifestaciones callejeras y cortes de calles, más que de huelgas generales.

Esta situación se modificó en noviembre de 2012 con la huelga general convocada por las tres centrales opositoras, que afectó a las principales ciudades del país, incluyendo Buenos Aires, mientras el crecimiento de la actividad económica se hacía más lento y aumentaban los precios. Fue la huelga general más importante desde 2002 y se produjo al mismo tiempo que, con una manifestación el 8 de noviembre, la fuerza social oligárquica, opositora al gobierno, intensificaba su ofensiva. También fueron importantes las cuatro huelgas generales convocadas por las tres centrales opositoras en 2014 y 2015. Algunos de los principales reclamos planteados en las huelgas de 2012 a 2015 - supresión del impuesto a las ganancias para los asalariados, extensión de la asignación universal por hijo a todos los asalariados y no sólo a los más pobres - remiten al interés inmediato de las capas menos pobres de los trabajadores. En abril de 2014 la CTA-Autónoma planteó por primera vez la oposición no sólo a medidas del gobierno sino al "modelo económico y social" del gobierno; la huelga fue importante incluso en gremios cuyos sindicatos no habían adherido, y hubo cortes de rutas y calles en todo el país; incluso la CGT-Alsina y la CTA de los Trabajadores, que apoyaban al gobierno, declararon su oposición al paro, pero no a los reclamos. La oposición al gobierno siguió aumentando en 2015, en que hubo dos huelgas generales con importante adhesión convocadas por la CGT-Azopardo, la CGT Azul y Blanca y la CTA Autónoma; en la primera de ellas también convocaron algunos gremios de la CGT-Alsina e independientes.

En síntesis, las huelgas generales de noviembre de 2012 y las cuatro de 2014 y 2015 muestran un mayor grado de unidad en la acción de una parte del movimiento

7. Sólo una de ellas, en octubre de 2010, convocada por la CTA todavía unida, tuvo otro motivo: el repudio al asesinato de un militante de izquierda por parte de un grupo sindical reunió en la Plaza de Mayo alrededor de 50.000 personas, contó con la participación de partidos de izquierda y organizaciones piqueteras tanto opositoras como adherentes al gobierno nacional. 
sindical, que, sin embargo permanece fracturado en cinco centrales, lo que se expresa en los apoyos dados a diferentes candidatos en las elecciones presidenciales de 2015.

\section{El movimiento obrero durante el gobierno Macri}

La fractura del movimiento sindical y de la alianza social popular signó ese momento descendente de la lucha de la clase obrera y abrió la puerta al retorno al gobierno de la fuerza social oligárquica de la mano de Mauricio Macri, que contó incluso con el apoyo abierto de Uatre (trabajadores rurales) y otros sindicatos enrolados en las 62 Organizaciones, y de la CG T Azul y Blanca, de los petroleros y, menos públicamente, de otros sindicatos de la CGT Azopardo. Por su parte los gremios agrupados en la CGT Alsina apoyaron la candidatura que se presentaba como continuidad de los gobiernos kirchneristas, pero los principales sindicatos de esa central pronto establecieron una fluida relación con el nuevo gobierno, que buscó establecer puentes con la CGT ${ }^{8}$. La CTA de los Trabajadores apoyó al candidato kirchnerista y la CTA Autónoma apoyó a su propio candidato presidencial.

$\mathrm{Al}$ mes de iniciado su gobierno Macri se reunió en la casa de gobierno con los principales dirigentes de las tres CGT: Hugo Moyano y Juan Carlos Schmid (CGT Azopardo); Antonio Caló, Armando Cavalieri y Gerardo Martínez (CGT Alsina); Luis Barrionuevo (CGT Azul y Blanca) y Gerónimo “Momo” Venegas (Uatre-62 Organizaciones). En agosto los dirigentes de las tres CGT participaron de un acto en el que el presidente anunció la devolución escalonada de aportes adeudados por el estado nacional por 29 mil millones de pesos del Fondo Solidario de Redistribución, que las obras sociales reclamaban por prestaciones realizadas desde 2002 y que el gobierno anterior no había devuelto (Jonquera, 2016). Paralelamente el gobierno anunció la creación de nuevos programas dirigidos a las capas más pobres y aumentó la cantidad de receptores en los programas preexistentes (Zommer, 2016).

8. Desde los años 1920 una parte del movimiento sindical establece relaciones fluidas con el gobierno de turno, cualquiera sea. Son los que tienen el suficiente poder como para ser convocados por todos los gobiernos y a la vez, los que tienen mucho que perder en términos materiales si enfrentan al gobierno. Entre ellos, algunos de los sindicatos del transporte, de los servicios públicos, empleados de comercio y una parte de los empleados estatales nacionales. Resultan ilustrativas las declaraciones de Juan Carlos Schmid, el 6 de abril de 2017: "no está en el ánimo de los sindicatos que se termine el mandato de nadie, no estamos proponiendo una fogata social [...] reiteramos nuestra vocación de diálogo porque el movimiento obrero siempre ha tenido espíritu negociador y porque si alguno nos quiere correr por izquierda diciendo que somos conservadores, efectivamente lo somos. Queremos conservar nuestros convenios colectivos, nuestras obras sociales, nuestros niveles de empleo y nuestra capacitación [...] tenemos que garantizar no sólo que haya gobernabilidad sino que la situación no se agrave porque los despidos los ponemos nosotros" (Bullrich, 2017).

9. Schmid es el máximo dirigente de la Confederación Argentina de Trabajadores del Transporte Catt). 
La CGT unificada en agosto de $2016^{10}$ y conducida por un triunvirato integrado por representantes de las principales tendencias (Héctor Daer por los "Gordos"11 e "Independientes", Juan Carlos Schmid por el "moyanismo" y Carlos Acuña por la CGT Azul y Blanca), estableció una relación de diálogo con el gobierno que se extendió todo el año 2016. Pero en ese año la economía se desplomó 2,3\%, la pobreza alcanzó al $32 \%$ y una inflación del $40 \%$ redujo los salarios y aumentó la desocupación. Pronto desapareció la unanimidad en esa política dialoguista dentro de la CGT, utilizando principalmente dos medios de lucha: las manifestaciones callejeras y la huelga general.

En 2016 hubo varias concentraciones y marchas multitudinarias en las que confluyeron la CGT, las CTA, la Corriente Sindical Federal (línea interna de la CGT integrada por los sindicatos bancario, de empleados de farmacias y encargados de edificios), los sindicatos docentes, el sindicato de camioneros y las OCp. Una de esas movilizaciones se realizó contra los despidos masivos y logró la aprobación en el Congreso de una ley "antidespidos", que fue vetada por el presidente Macri.

En marzo de 2017 se sucedieron las protestas convocadas por organizaciones sindicales (el 7, 200.000 manifestantes insultaron a los secretarios generales de la CGT, reclamando que pusieran fecha a la huelga general anunciada desde febrero), de mujeres y de derechos humanos, todas ellas con un fuerte tinte antigubernamental. La protesta culminó el 6 de abril, con la primera huelga general contra la política económica del gobierno de $\mathrm{Macri}^{12}$, convocada por la CGT, en la que confluyeron las distintas corrientes sindicales (excepto las oficialistas 62 Organizaciones y petroleros), y que tuvo una alta adhesión en todo el país. El diario oficialista Clarín admitió que las calles de las principales ciudades estuvieron despobladas y hubo altos índices de ausentismo en fábricas, empresas y escuelas. Esta huelga presenta rasgos que se van a reiterar en las siguientes: son convocadas "sin movilización" por la CGT, cuyas direcciones históricamente tienden a privilegiar la negociación con los gobiernos (ver nota 8); pero las CTA, algunos sindicatos y partidos de izquierda cortan calles y manifiestan, lo que da lugar a choques con tropas policiales y otras fuerzas armadas del gobierno. Otro rasgo que se reitera es la adhesión de las OCP, en este caso el llamado "Triunvirato Piquetero" formado por la Confederación de Trabajadores de la Economía Popular (Ст EP), Barrios de Pie (вdP) y la Corriente Clasista y Combativa (CCC), uniéndose en la acción el activo y la reserva de la clase obrera.

10. Votaron 1582 congresales sobre un total de 2191; se unieron 124 sobre 213 organizaciones confederadas. Es decir, quedaron afuera 89 sindicatos (Balinoti, 2019b). No participaron los sindicatos enrolados con el gobierno (62 Organizaciones).

11. Con ese nombre se conoce a los grandes sindicatos de empleados de comercio, de la sanidad, de la alimentación, de la energía eléctrica y ferroviarios.

12. Según el Indec, en el segundo trimestre de ese año la desocupación abierta alcanzaba al 8,7\%. 
La CGT se distanció de los incidentes pero rechazó la represión gubernamental, al mismo tiempo que manifestó su vocación por seguir dialogando con el gobierno.

El resto del año 2017 hubo manifestaciones multitudinarias como la que repudió la política "de seguridad" del gobierno y reclamó la aparición de Santiago Maldonado ${ }^{13}$.

La más importante de esas movilizaciones, que desbordó el sistema institucional y constituyó un punto de inflexión, se desarrolló entre el 13 y el 18 de diciembre. Incluyó una huelga general que pasó casi desapercibida por la manera en que fue convocada por una parte de la CGT y por los enfrentamientos callejeros que constituyeron el hecho principal de rechazo a una ley impulsada por el gobierno nacional que modificó el cálculo de actualización de las jubilaciones. En la decisión de convocar al paro influyó el hecho de no haber sido consultada la CGT en la elaboración del proyecto de reforma así como el empeoramiento de la situación de los jubilados ${ }^{14}$. Miles de manifestantes marcharon hacia el edificio del Congreso donde fueron contenidos por un enorme operativo de la Policía de la Ciudad. Los manifestantes rompieron veredas, bancos y estatuas de la plaza del Congreso para pertrecharse y arrojaron bombas molotov; la policía atacó con gases y balas de goma, mientras los manifestantes levantaban barricadas con maderas tomadas de obras en construcción. El enfrentamiento se prolongó por horas. Hubo 109 heridos, y la policía de la Ciudad declaró 77 agentes heridos; fueron apresadas 60 personas. $\mathrm{Al}$ anochecer comenzó un cacerolazo en distintos barrios de Buenos Aires y frente a la Quinta Presidencial, que culminó en otra concentración multitudinaria y vigilia frente al Congreso, mientras seguía el debate en el recinto. Finalmente la ley fue aprobada. Aunque con diferencias a su interior ${ }^{15}$ la convocatoria de la CGT, las CTA y las OCP mostró un alto grado de unidad en la acción. Y los choques callejeros del 14 y 18 mostraron la disposición al enfrentamiento. La lucha popular volvió a darse por fuera del sistema institucional, como no ocurría desde 2002. Se estableció un límite a las políticas que pretendía instaurar el gobierno nacional después de su triunfo en las elecciones parlamentarias de ese año: una profundización de la reforma del sistema jubilatorio (extendiendo la edad de jubilación), la reforma laboral (que establecería peores condiciones para los trabajadores asalariados) y la reforma impositiva quedaron postergadas sine die.

13. Maldonado participaba de una protesta de mapuches cuando desapareció en medio de un ataque de la Gendarmería Nacional. Su cuerpo fue encontrado ahogado dos meses y medio después.

14. La nueva ley modificaba la manera de calcular los aumentos de las jubilaciones y, en lo inmediato, reducía ese aumento.

15. La CGT declaró que "la violencia de los grupos radicalizados impide que los trabajadores organizados, jubilados y ciudadanos, descontentos con el proyecto de ley en tratamiento, pudieran expresar libre y pacíficamente su oposición. La CGT no participa ni comparte la violencia como forma de protesta”. 
Al terminar el año 2017 el 26,6\% de la población se encontraba bajo la línea de pobreza; la desocupación abierta era de 7,2\% y la subocupación 10,2\%; la inflación anual era de 24,8\%. Un año después la pobreza alcanzaba al 33,6\% (UCA, 2018). Y en el cuarto trimestre la desocupación abierta era de 9,1 y la subocupación 12\% (Indec). Y la inflación anual era de 47,65\%.

En 2018 hubo varias marchas multitudinarias, entre ellas la Marcha de Mujeres, que tomó un carácter fuertemente antigubernamental. En junio, después que el poderoso Sindicato de Choferes de Camiones se retiró del Consejo Directivo de la CGT por la reticencia de éste a convocar a una huelga general, la central sindical la declaró "sin movilización” para el 25. Esta vez la decisión de convocar a la huelga general no tuvo disidencias dentro de la CGT; los dirigentes argumentaron que servía "para descomprimir" la presión de las bases, en una situación sin margen para negociar, en un momento en que la desocupación abierta era de 9,6\%, y el acuerdo firmado con el Fondo Monetario Internacional contemplaba la implementación de políticas de ajuste fiscal. La huelga fue masiva y, nuevamente, los sindicatos clasistas, los partidos de izquierda y las OCP se movilizaron.

En septiembre el Sindicato de Camioneros, los mecánicos (SMATA) y la Corriente Federal formaron el Frente Sindical para el Modelo Nacional (FSMN). Poco después, el triunviro Juan Carlos Schmid renunció a la secretaría general de la CGT.

La profundización de la crisis económica y social, y el acuerdo firmado por el gobierno nacional con el FMI, que contemplaba la implementación de políticas de ajuste fiscal, llevó al Consejo Directivo de la CGT a convocar a una nueva huelga general para el 25 de septiembre, reiterando los reclamos ya nombrados, contra todo intento gubernamental y patronal de imponer una reforma laboral y por medidas a favor de las pequeñas y medianas empresas. Las CTA declararon la huelga por 36 horas, comenzando el 24, y se movilizaron en las calles. La huelga general recibió el apoyo de todas las fracciones político-sindicales, excepto Uatre y las 62 Organizaciones, integrantes de la alianza en el gobierno, y tuvo un acatamiento masivo.

Mientras tanto la situación de las clases populares seguía empeorando. Según el Observatorio de la Deuda Social de la UCA, en el primer semestre de 2019 la pobreza alcanzó a 35,4\% (14,4 millones de personas) y la indigencia a 7,7\% (subió 2,8 puntos) (Jueguen, 2019a); en el tercer trimestre es de 40,8\% (Jueguen, 2019b). En el segundo trimestre de ese año la desocupación alcanzaba al 10,6\% y la subocupación a 13,1\% (Indec). Y la inflación anual alcanzó casi el 54\%.

El 4 de abril la CGT encabezó en la ciudad de Buenos Aires una "Marcha por la unidad, la producción y el trabajo argentino" contra la política económica del gobierno. La convocatoria sintetiza sus demandas y su proyecto de país: 
Preocupados por la situación económica y social, marchamos por más trabajo decente y en relación de dependencia; por mejores salarios, programas sociales y jubilaciones; por más producción nacional; por un país que priorice el desarrollo productivo y (en donde) se castigue (la) especulación financiera; por más desarrollo agropecuario con valor agregado; por una política fiscal y monetaria definida para incentivar la producción, el trabajo y el crecimiento del mercado interno; por servicios públicos de calidad y con tarifas socialmente sustentables; por entender que tanto la salud, la educación y la Justicia son pilares fundamentales de la sociedad; por impuestos a las ganancias que no destruyan el salario, y por un país para todos y no para unos pocos. (Balinoti, 2019a).

La movilización fue un despliegue no coordinado de amplias columnas, con distintas metas: mientras la CGT, acompañada por empresarios de la Confederación General Empresaria (CGERA) y la Asociación de Empresarios Nacionales para el Desarrollo Argentino, marchó al Congreso nacional donde entregó proyectos de ley sobre emergencia alimentaria y promoción de la actividad de las pequeñas y medianas empresas, las OCP (BdP, PO) y partidos de izquierda, que se enfrentaron con la policía, reclamaron una huelga general de 36 horas y la ampliación de los planes sociales; los sindicatos agrupados en el FSMN y las CTA reclamaron una huelga general por 24 horas lo mismo que los sindicatos agrupados en la Catt y en la Federación Marítima, Portuaria y de la Industria Naval de la República Argentina (Fempinra). Una aparente dispersión que, sin embargo, terminaba uniendo a todos en la acción.

Esta marcha multitudinaria impulsó al FSMN y las CTA a convocar una huelga general para el 30 de abril, en rechazo al proyecto oficial de reforma laboral y por paritarias libres y aumento del salario mínimo, resguardo de la industria nacional, de la pequeña y mediana empresa y las economías regionales, la declaración de la emergencia ocupacional, alimentaria y sanitaria y el repudio al acuerdo con el FMI. Aunque parcial, la huelga tuvo fuerte adhesión en el transporte, la administración pública, la docencia, la banca y en la industria automotriz y la del neumático. Al día siguiente, $1^{\circ}$ de mayo, el FSMN instaló 300 ollas populares en la ciudad de Buenos Aires.

A fines de ese mes, el 29 de mayo, la CGT convocó a otra huelga general "sin movilización", reiterando demandas anteriores. La respuesta inmediata del gobierno, que adelantó la entrega de fondos adeudados a las obras sociales sindicales, no resultó suficiente para rever la medida de fuerza. Adhirieron las CTA, pero llamando también a la movilización y el Triunvirato Piquetero y el FSMN instalaron ollas populares. Hubo movilizaciones y actos reclamando la inmediata convocatoria a una huelga general por 36 horas y criticando a la conducción de la CGT por haber convocado a la huelga general "no para derrotar el ajuste, sino para descomprimir la bronca popular por los despidos y suspensiones, la inflación y los tarifazos, el hambre y la pobreza” (Tosi, 2019). 


\section{Consideraciones finales}

La fractura de la fuerza social democrático popular a partir de 2011 permitió el retorno de la fuerza social oligárquica al gobierno, con el apoyo de algunos sindicatos. Incluso los principales sindicatos que habían apoyado la candidatura opuesta dialogaron con el nuevo gobierno. Éste devolvió parte de la deuda que el gobierno anterior tenía con las obras sociales sindicales e incrementó los subsidios a la capa más pobre del proletariado, a la vez que proclamaba la necesidad de "flexibilizar" las relaciones laborales, abaratar el precio de la fuerza de trabajo, modificar el régimen jubilatorio e impositivo, favoreciendo a los más ricos.

Los resultados de su política económica se hicieron sentir: una caída de la actividad, aumento de la desocupación, fuerte inflación con deterioro del salario real e importante crecimiento de la pobreza. Pronto comenzaron las protestas, tanto de la capa más acomodada de la clase obrera como de la más pobre, que en general se movilizaron conjuntamente a pesar de las numerosas fracciones político-sindicales en que estaban divididas.

Durante el primer año las direcciones de las tres CGT mantuvieron un fluido diálogo con el nuevo gobierno. Pero realizaron marchas y manifestaciones reclamando contra los despidos, la inflación que licuaba los salarios y el impuesto a las ganancias, de las que también participaron las CTA, las OCP y las agrupaciones de izquierda. La unidad en la acción cuajó en la unificación de las tres CGT (Azopardo, Alsina y Azul y Blanca) en agosto de 2016, unidad que no incluyó a los sindicatos alineados en la alianza política del gobierno (las "62 Organizaciones").

La descripción de las seis huelgas generales, cinco de ellas declaradas por la dirección de la CGT con la adhesión de las distintas vertientes de la CTA y la participación en la movilización callejera de las $\mathrm{OCP}$, muestra que fueron la culminación de momentos de auge de la protesta popular contra el gobierno. Sólo una (30/4/2019) no fue convocada por la CGT. Sin embargo, la convocatoria de la CGT lejos estuvo de reflejar unanimidad en su dirección: en la segunda y la cuarta una parte de su dirección fue reticente a declarar la huelga y la quinta fue declarada al margen de la CGT. Aunque en las movilizaciones cada sector lo hizo por separado se logró un alto grado de unidad en la acción contra las políticas del gobierno.

A pesar de que la CGT convocó a las huelgas generales "sin movilización" hubo manifestaciones callejeras en todas ellas, llamadas por las CTA, algunos sindicatos y corrientes sindicales (Corriente Federal, FSM), las OCP y, en ocasiones, organizaciones empresarias. Hemos destacado los combates callejeros de diciembre de 2017 que desbordaron el sistema institucional y frenaron las reformas que impulsaba el gobierno. 
Un rasgo que diferencia a la segunda mitad de la década de 2010 del inicio del siglo es que una parte importante del movimiento sindical (FSM, Corriente Federal, Sindicato de Camioneros, bancarios y otros, y al menos una parte de la CGT) se movilizó conjuntamente con las OCP e incluso hay vínculos permanentes con el Triunvirato Piquetero, que plantea su incorporación a la CGT.

Las demandas sindicales planteadas apuntaron a reivindicaciones económicas inmediatas (paritarias libres, contra despidos) pero también contra la política económica del gobierno en general, especialmente contra la implementación de las reformas laboral, jubilatoria y tributaria y el acuerdo con el FMI. También puede observarse la alianza con organizaciones económico-corporativas de fracciones del capital contra la apertura de las importaciones ${ }^{16}$. A medida que la inflación destruía los salarios el reclamo de paritarias mensuales fue ganando terreno junto a la demanda de cambio en la política económica. A la vez se consolidó la unidad en la acción del conjunto de la clase obrera, en sus capas más acomodadas y en sus capas más pobres.

La manifestación del 4 de abril de 2019 fue una demostración de fuerza del conjunto del movimiento obrero y la huelga general del 29 de mayo el punto culminante de la unidad del grupo social, con la participación y adhesión del conjunto de las fracciones políticas dentro del movimiento sindical y de las OCP, en una coyuntura de profundización de la crisis social y económica y apertura de la campaña política con motivo de las elecciones presidenciales de este año.

A partir de entonces la mayor parte del movimiento obrero y las OCP centraron sus acciones en la confrontación electoral, impulsando la unidad del peronismo en tanto fuerza política, persistiendo al mismo tiempo la presión de cuadros sindicales de base que, con el apoyo de partidos de izquierda, plantearon la necesidad de profundizar las acciones de protesta con la convocatoria inmediata a una nueva huelga general.

En julio, agosto y septiembre hubo numerosas movilizaciones, convocadas por el Triunvirato Piquetero y otras organizaciones, reclamando que se declarara la emergencia alimentaria; pero todo se canalizó en el enfrentamiento electoral de octubre, que culminó con la derrota del gobierno. Las distintas corrientes sindicales, excepto las 62 Organizaciones y las de izquierda, apoyaron la candidatura victoriosa de Alberto Fernández.

Triunfante la alianza política que tiene como componente principal al peronismo, el movimiento obrero se encamina a un nuevo proceso de unificación institucional, que puede, incluso, abarcar a la CTA de los Trabajadores, después de 28 años de ruptura, y a una parte de las OCP.

16. La conciencia de asalariado que prima en el movimiento obrero argentino lo hace el principal impulsor del interés del capital industrial que opera en el mercado interno frente al capital más concentrado y vinculado al mercado mundial. 


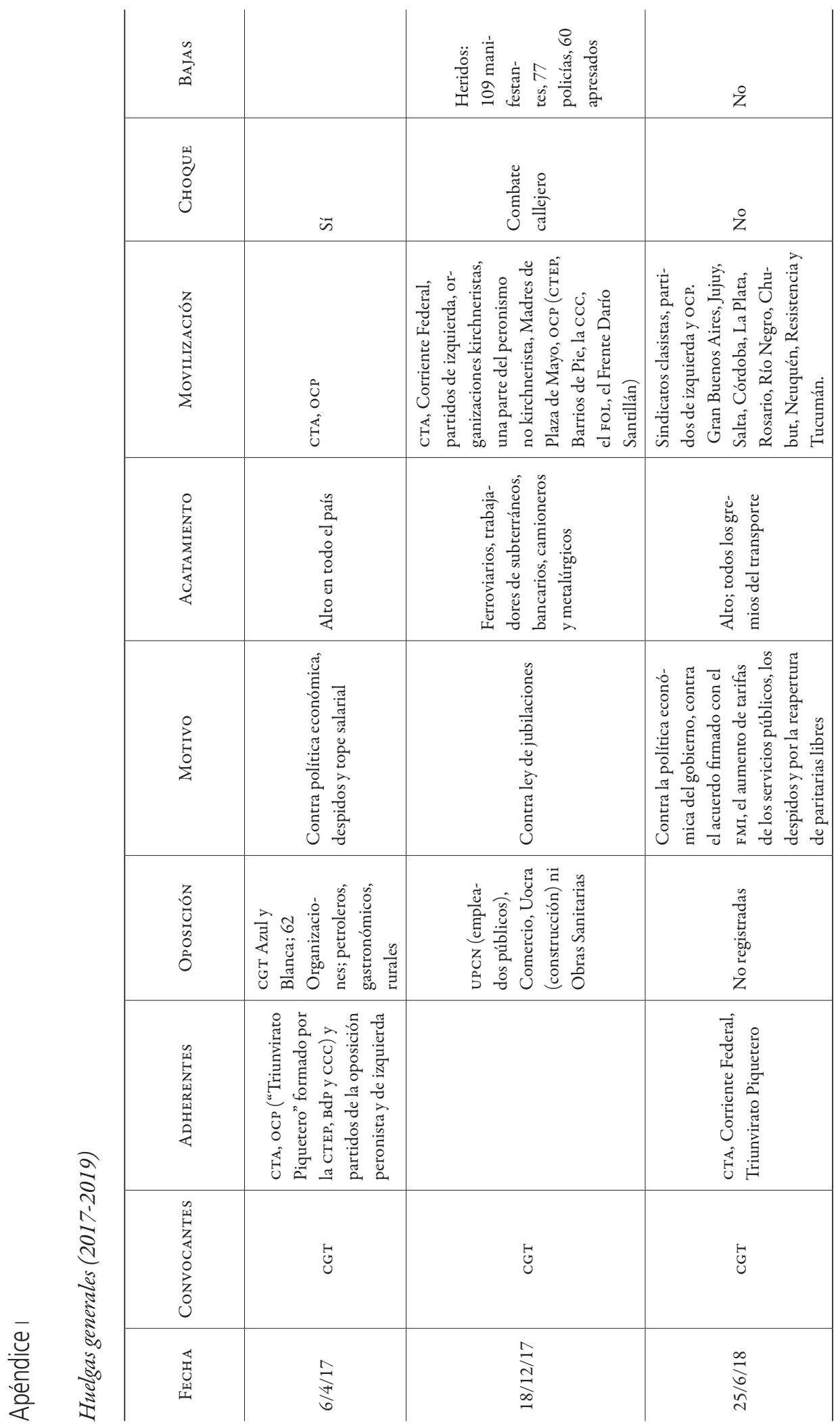




\begin{tabular}{|c|c|c|c|}
\hline 敢 & $\stackrel{\circ}{z}$ & $\stackrel{\circ}{z}$ & 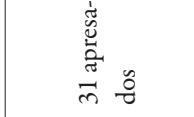 \\
\hline $\begin{array}{l}\text { 山्山 } \\
\text { O } \\
\text { गु }\end{array}$ & $\dot{z}$ & $\stackrel{\circ}{Z}$ & 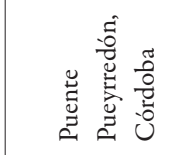 \\
\hline 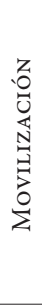 & 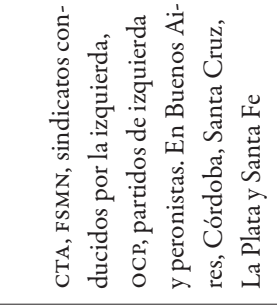 & 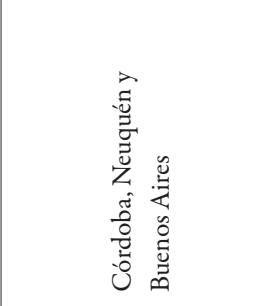 & 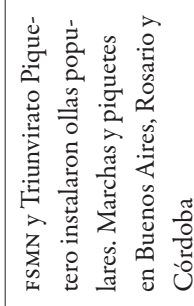 \\
\hline 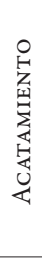 & 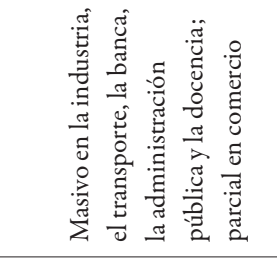 & 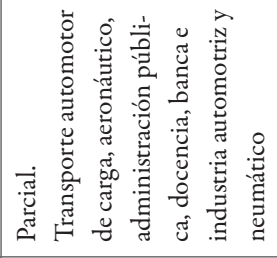 & 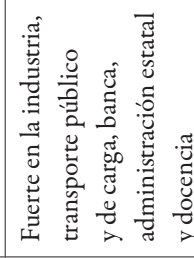 \\
\hline 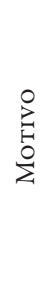 & 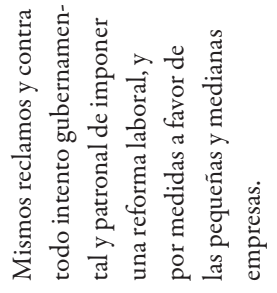 & 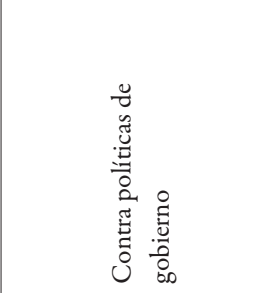 & \\
\hline $\begin{array}{l}z \\
0 \\
0 \\
0 \\
0 \\
0 \\
0\end{array}$ & 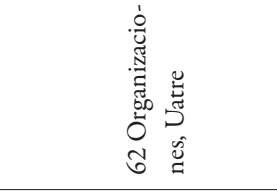 & 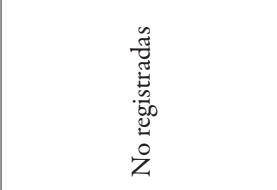 & 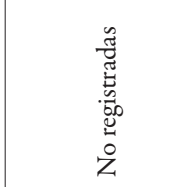 \\
\hline 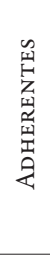 & 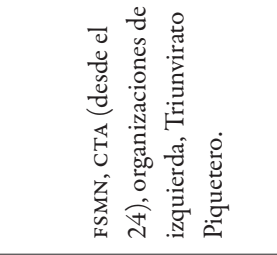 & $\overleftrightarrow{\Delta}$ & 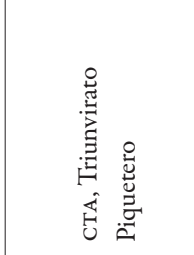 \\
\hline 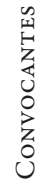 & 竎 & 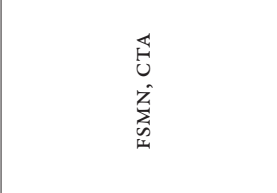 & 矛 \\
\hline 焉 & 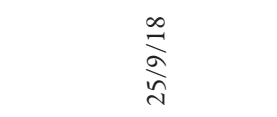 & $\underset{\frac{a}{\partial}}{\stackrel{\vec{p}}{\partial}}$ & $\frac{a}{\stackrel{i}{a}}$ \\
\hline
\end{tabular}




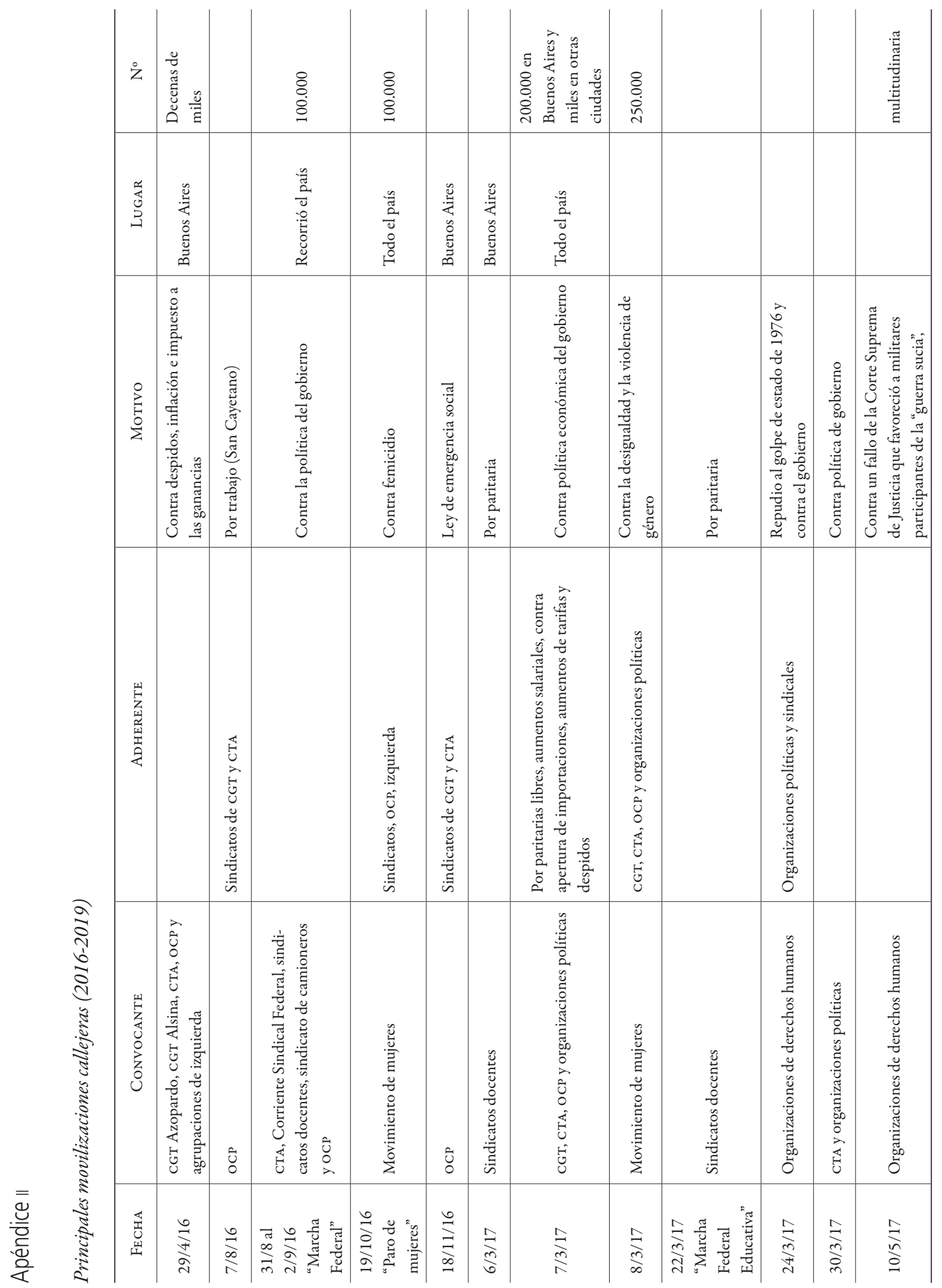




\begin{tabular}{|c|c|c|c|c|c|c|c|c|c|c|c|c|}
\hline$\dot{z}$ & 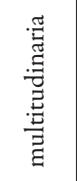 & 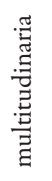 & $\begin{array}{l}8 \\
0 \\
0 \\
\\
\end{array}$ & & $\begin{array}{l}8 \\
0 \\
\dot{0} \\
\stackrel{+}{1}\end{array}$ & & & & & & 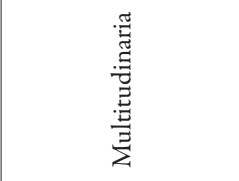 & \\
\hline 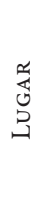 & 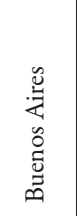 & & 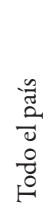 & 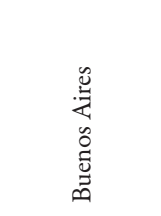 & $\begin{array}{l}\frac{n}{a} \\
\frac{a}{2} \\
\frac{1}{0} \\
0 \\
0 \\
0 \\
1\end{array}$ & 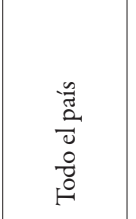 & 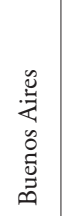 & 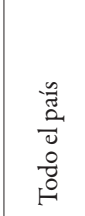 & 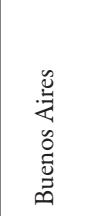 & 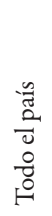 & 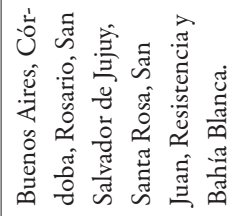 & 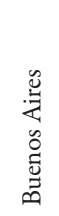 \\
\hline $\begin{array}{l}\stackrel{0}{\Delta} \\
\stackrel{0}{\Sigma}\end{array}$ & 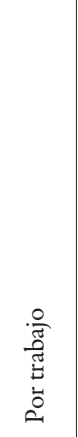 & & 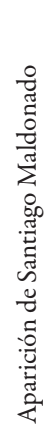 & & 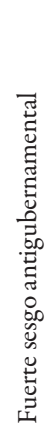 & & 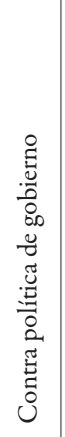 & 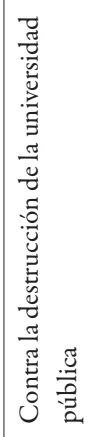 & 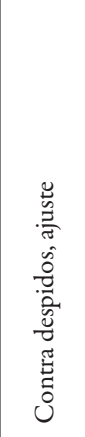 & 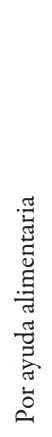 & 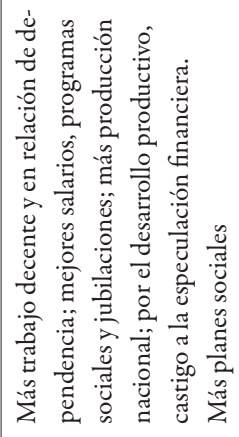 & \\
\hline 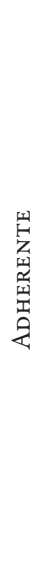 & 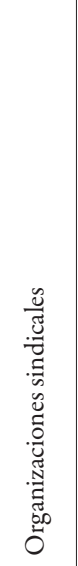 & 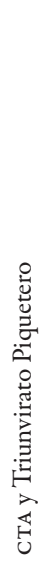 & & & & & & & & & 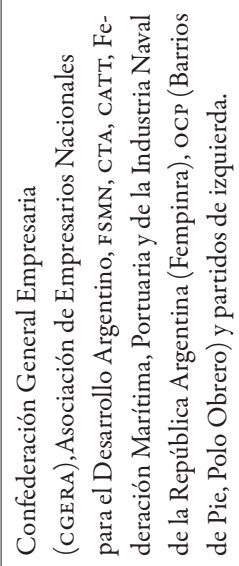 & \\
\hline 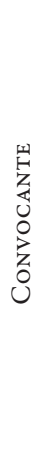 & 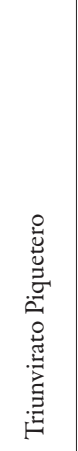 & $\vec{y}$ & 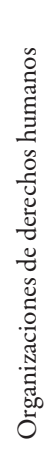 & 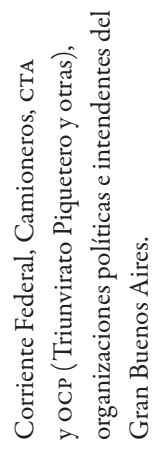 & 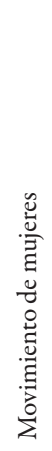 & 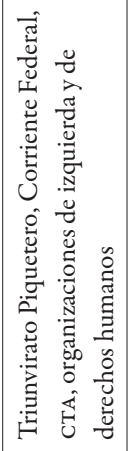 & 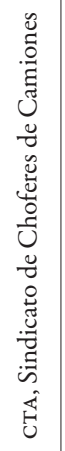 & 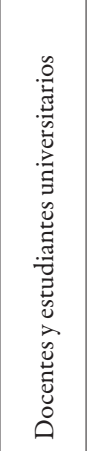 & 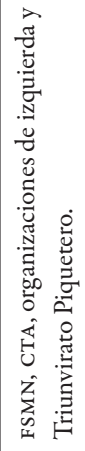 & 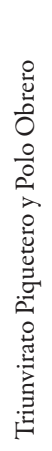 & $\begin{array}{l}\vec{y} \\
\text { U }\end{array}$ & 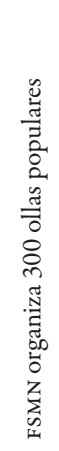 \\
\hline 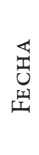 & 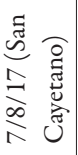 & $\frac{\hat{\infty}}{\stackrel{\Delta}{\lambda}}$ & $\stackrel{\curvearrowright}{\lesssim}$ & $\underset{⿱ 亠}{\stackrel{\infty}{\Delta}}$ & $\frac{\infty}{\infty}$ & 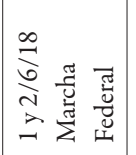 & $\begin{array}{l}\stackrel{\infty}{\leftrightarrows} \\
\stackrel{ \pm}{ \pm}\end{array}$ & $\underset{\substack{\infty \\
\stackrel{\infty}{\infty}}}{\stackrel{\infty}{\infty}}$ & 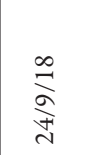 & 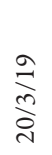 & 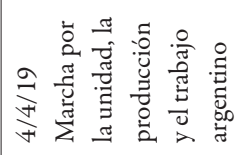 & 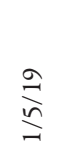 \\
\hline
\end{tabular}




\section{Referencias Bibliográficas}

BALINoti, Nicolás. (2019a), "La CGT desafía a Macri con una movilización y amenaza con otro paro". La Nación, 4 /4. Disponible en https://www.lanacion.com.ar/politica/la-cgt-desafia-a-macri-con-una-movilizacion-y-amenaza-con-otro-paro-nid2235019.

BALINOTI, Nicolás. (2019b), "Fernández le pide a la CGT una tregua hasta que se reactive la economía”. La Nación, 8/11. Disponible en https://www.lanacion.com.ar/politica/ fernandez-le-pide-a-la-cgt-una-tregua-hasta-que-se-reactive-la-economia-nid2304547.

BERMúdEZ, Ismael. (1998), “La inseguridad económica hace enojar a los ministros”. Clarín, 14/11. BULLRICH, Lucrecia. (2017), "La CGT buscó mostrar unidad y calificó el paro de 'contundente”, La Nación, 7/4. Disponible en https://www.lanacion.com.ar/politica/la-cgt-busco-mostrar-unidad-y-califico-el-paro-de-contundente-nid2006045.

Cotarelo, María Celia. (1999), "El motín de Santiago del Estero. Argentina, diciembre de 1993". Pimsa, Buenos Aires. Disponible en www.pimsa.secyt.gov.ar.

Cotarelo, María Celia. (2016), Argentina 1993-2010: el proceso de formación de una fuerza social. Buenos Aires, Imago Mundi.

Cotarelo, María Celia \& IÑigo Carrera, Nicolás. (2005), "Algunos rasgos de la rebelión en Argentina 1993-2001”. Pimsa-Documentos y Comunicaciones 2004, Buenos Aires. Disponible en www.pimsa.secyt.gov.ar.

Donaire, Ricardo; Rosati, German; Cavalleri, Stella \& Mattera, Pablo. (2018), “Superpoblación relativa en Argentina: construcción de un instrumento para su relevamiento sistemático y estandarizado". Pimsa-Documentos y Comunicaciones 2016, Buenos Aires. Disponible en http://www.pimsa.secyt.gov.ar/publicaciones/DT_2016_94.pdf.

GalaK, Oliver. (2007), "Habría unos 500.000 pobres más que los que mide el Indec". La Nación, 13/8. Disponible en https://www.lanacion.com.ar/economia/habria-unos-500000-pobres-mas-que-los-que-mide-el-indec-nid934046.

GómEZ, Elizabeth \& KINDGARD, Federico. (1998), “Los cortes de ruta en la provincia de Jujuy. Mayo/junio de 1997”. Pimsa-Documentos y Comunicaciones 1998, Buenos Aires. Disponible en www.pimsa.secyt.gov.ar.

INDEC. Disponible en www.indec.gov.ar.

IÑIgo CARRERA, Nicolás. (2002), “Las huelgas generales, Argentina 1983-2001: un ejercicio de periodización”. Pimsa-Documentos y Comunicaciones 2001, Buenos Aires. Disponible en www.pimsa.secyt.gov.ar.

IÑigo CARrera, Nicolás. (2010), "El movimiento orgánico de la estructura de la sociedad argentina”. In: Maya, Margarita López; Figueroa, Carlos \& Rajland, Beatriz (eds.). Temasy procesos de la historia reciente de América Latina. Buenos Aires/Santiago de Chile, Clacso/Arcis. Jonquera, Miguel. (2016), “Un gesto para acercarse a los sindicatos”. Página12: 5, 3/8. Disponible en https://www.pagina12.com.ar/diario/elpais/1-305898-2016-08-03.html. 
Jueguen, Francisco. (2019a), "La pobreza subió a 35,4\% y afecta a 14,4 millones de argentinos". La Nación, 30/9. Disponible en https://www.lanacion.com.ar/economia/pobreza-indec-primer-semestre-nid2292717.

Jueguen, Francisco. (2019b), “La pobreza en la Argentina llega al 40,8\%, según la UCA”. La Nación, 5/12. Disponible en https://www.lanacion.com.ar/economia/para-uca-macri-deja-su-presidencia-pobreza-nid2313036.

Klachкo, Paula. (2002), “Conflictividad social en Argentina: Cutral-Có y Plaza Huincul. 1996-1997”. In: Levy, Betina et al. Crisis y conflicto en el capitalismo latinoamericano. Buenos Aires, Clacso/Asdi.

Kulfas, Matías. (2016), Los tres kirchnerismos, una historia dela economía argentina 20032015. Buenos Aires, Siglo XXI.

Marx, Karl. ([1867] 1983), El Capital. México, Siglo Xxi.

Polischuk, Sebastián \& RoJze, Patricio. (2017), “La protesta obrera en Tartagal y General Mosconi: un análisis del corte de ruta de mayo de 1997”. Pimsa-Documentos y Comunicaciones 2015, Buenos Aires. Disponible en http://www.pimsa.secyt.gov.ar/publicaciones/ DT_2015_92.pdf.

STANG, Silvia. (2007), “Otro dato polémico: sólo el 23,4\% de la gente sería pobre”. La Nación, $21 / 9$.

TARrow, Sidney. (1998), Power in movement: social movements and contentious politics. Nova York, Cambridge University Press.

Tomada, Carlos; Schleser, Diego \& Maito, Matías. (2018), Radiografía de la sindicalización en Argentina. Cetyd-Unsam. Disponible en http://noticias.unsam.edu.ar/wp-content/ uploads/2018/10/sindicalizacion.pdf.

Tosi, Nicolás. (2019), "La izquierda expresó su protesta con cortes de calles”. La Nación, 30/5. Disponible en https://www.lanacion.com.ar/politica/la-izquierda-expreso-su-protesta-con-cortes-de-calles-nid2252851.

UcA. (2018), Observatorio de la Deuda Social Argentina; Disponible en http://wadmin. uca.edu.ar/public/ckeditor/Observatorio\%20Deuda\%20Social/Presentaciones\%20 2018/2018/2018-Observatorio-Informe-POBREZA-MONETARIA-EDSA-ODSA-2010-2018.pdf.

Zommer, Laura. (2016), “Con el nuevo gobierno aumentaron los planes sociales y la pobreza”. La Nación, 10/10. Disponible en https://www.lanacion.com.ar/politica/con-el-nuevo-gobierno-aumentaron-los-planes-sociales-y-la-pobreza-nid1945574.

\section{Resumen}

El movimiento obrero organizado ante la ofensiva de la oligarquía financiera: Argentina, 2016-2019 En diciembre de 2015 retornó al gobierno la fuerza social acaudillada por la oligarquía financiera 
dando continuidad al período contrarrevolucionario iniciado a mediados de la década de 1970 que acompaña el desarrollo del capitalismo predominantemente en profundidad y genera una creciente masa de población sobrante para las necesidades del capital. Ese retorno, en un momento descendente de la lucha de la clase obrera, fue posible por la fractura del movimiento sindical y de la alianza social popular. Los resultados de la política económica del nuevo gobierno fueron una fuerte caída de la actividad productiva, aumento de la desocupación, fuerte inflación con deterioro del salario real e importante crecimiento de la pobreza. Pronto comenzaron las protestas, tanto de la capa más acomodada de la clase obrera como de la más pobre, que en general, y a diferencia de las décadas anteriores, no sólo se movilizaron conjuntamente sino establecieron relaciones orgánicas, a pesar de las numerosas fracciones político-sindicales en que estaban divididas. La resistencia se manifestó en seis huelgas generales y numerosas protestas callejeras entre las que se destaca la de diciembre de 2017, que desbordó el sistema institucional. Las demandas sindicales planteadas apuntaron a reivindicaciones económicas inmediatas (paritarias libres, contra despidos) y contra la política económica del gobierno en general, especialmente contra la implementación de las reformas laboral, jubilatoria y tributaria y el acuerdo con el FMI.

Palabras-clave: Movimiento obrero; Argentina; Huelgas generales; Conflicto social; Políticas neoliberales.

\section{Abstract}

Trade union movement and the attack from financial oligarchy: Argentine, 2016-2019

On December 2015 the social force led by the financial oligarchy returned to the government, giving continuity to the counterrevolutionary period that started in the mid-seventies. Among its main features are the expansion of capitalism in depth and the generation of an increasing surplus population. Its return was made possible by the division of the trade union movement and the popular social alliance. The new government's policy gave way to an important decline of productive activity, a fall of wages produced by inflation and an important increase of unemployment and poverty. Soon protests began, performed by all the layers of the working class, moving together and establishing organic relations between them. Six general strikes and numerous street demonstrations were the main forms of resistance, which included one in December 2017 that overflowed the institutional system. Unions demands were for immediate economic goals (free discussion of salaries, against layoffs) and against the government's economic policy, especially against labor, retirement and tax reforms, and the agreement with the IMF.

Keywords: Trade-unions; Argentina; General strikes; Social conflict; Neoliberal policies.

\section{Resumo}

O movimento sindical organizado diante da ofensiva da oligarquia financeira: Argentina, 2016-2019

Em dezembro de 2015, a força social liderada pela oligarquia financeira retornou ao governo argentino dando continuidade ao período contrarrevolucionário iniciado em meados da década 
de 1970 que acompanha o desenvolvimento do capitalismo predominantemente e em profundidade e gera uma massa crescente de população excedente para as necessidades de capital. Esse retorno, em um momento decadente da luta da classe trabalhadora, foi possibilitado pela fratura do movimento sindical e da aliança social popular. Os resultados da política econômica do novo governo foram uma queda acentuada da atividade produtiva, aumento do desemprego, inflação forte com deterioração dos salários reais e crescimento significativo da pobreza. Logo começaram os protestos, tanto da camada mais remediada da classe trabalhadora quanto da mais pobre, que em geral, e diferentemente das décadas anteriores, não apenas se mobilizaram juntas, mas estabeleceram relações orgânicas, apesar de numerosas frações político-sindicais em que estavam divididas. A resistência se manifestou em seis greves gerais e numerosos protestos de rua, incluindo o de dezembro de 2017, que transbordou o sistema institucional. As demandas sindicais apontaram para demandas econômicas imediatas (paritárias livres, contra demissões) e contra a política econômica do governo em geral, principalmente contra a implementação de reformas trabalhistas, de aposentadoria e tributação e o acordo com o FMI.

Palavras-chave: Sindicalismo; Argentina, Greves gerais; Conflito social; Políticas neoliberais

Texto recebido em 13/12/2019 e aprovado em 14/1/2020.

DOI: $10.11606 / 0103-2070 . t s .2020 .165055$.

Nicolás IÑigo Carrera es profesor en historia (Universidad de Buenos Aires). Posgrado en Investigación en Desarrollo Urbano y Regional (Ceur-Instituto Di Tella). Investigador Principal de Consejo Nacional de Investigaciones Científicas y Técnicas (Conicet) con asiento en el Instituto Emilio Ravignani (FFyL-UBA). Miembro fundador del Programa de Investigación sobre el Movimiento de la Sociedad Argentina (Pimsa).E-mail: carreranico@gmail.com.

FABIÁN FERNÁNDEZ es profesor en enseñanza media y superior en historia (FFyL-UBA), Jefe de trabajos prácticos (Facultad de Ciencias Sociales - UBA), Investigador del Programa de Investigación sobre el Movimiento de la Sociedad Argentina (Pimsa).E-mail: faleofer@hotmail.com.

María Celia Cotarelo es doctora en ciencias sociales y profesora de historia de la Universidad de Buenos Aires. Miembro fundadora y directora del Programa de Investigación sobre el Movimiento de la Sociedad Argentina (Pimsa) de Buenos Aires desde 2019. Autora del libro Argentina 1993-2010: el proceso de formación de una fuerza social y co-compiladora del libro La revolución en el Bicentenario: reflexionando sobre la emancipación, los grupos y clases subalternas, entre otras publicaciones. E-mail: mccotarelo@gmail.com. 